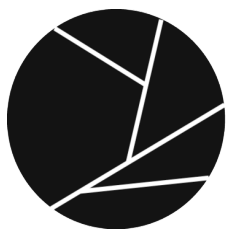

\title{
SOPHIA
}

PEER REVIEW JOURNAL

VISUAL SPACES OF CHANGE: DESIGNING INTERIORITY

SHELTER, SHAPE, PLACE, ATMOSPHERE

ISSN: 2183-8976 [PRINT] 2183-9468 [ONLINE]

Volume 5, Issue 1| Publication year: 2020

DOI 10.24840/2183-8976_2020-0005_0001_7

(c) SCOPIO EDITIONS

HOMEPAGE:

\section{In praise of light and shadows}

\section{by Nuno Grande}

The interaction of light and shadow has always fascinated architects, and even more so since Le Corbusier's famous quote from 1923, published in Vers une Architecture, in which he describes architecture as "the learned game, correct and magnificent, of forms assembled in the light". This game, which thus motivated the painters of Purism and Cubism - among whom Le Corbusier would come to be included - contributed in great part to the definition of the aesthetic ideals of the artistic avant-garde in the West in the first half of the 20th century. Associated with the purity of crystal, with the idea of total transparency, and with the blurring of the boundaries between the interior and the exterior, this very same game served as the conceptual premise of (and later as a critical challenge to) the architecture of the Modern Movement.

The counterpoint to the purist and crystalline impetus of modernism would emerge, and 
indeed one of many, by way of "In Praise of Shadows", a reference to the book written in 1933 by Junichiro Tanizaki. In this work, the author examines how Oriental culture (in contrast with Western culture) has always sought to shield the interior space from the invasion of light and from exterior views by use of trees, porches, patios, shutters, and translucent sliding doors or dividers (the Japanese shôji). It is not by accident that many of these traditional elements would once again come to be adopted by Western architecture from the late 1950s onward in its search for vernacular values deriving from a broad variety of cultures.

Having studied in these seminal years of critical review of the Modern Movement and coinciding with the publication of the Survey on Regional Architecture in Portugal - (Inquérito à Arquitetura Popular em Portugal) (1955-1961), the young architect Álvaro Siza learned from Fernando Távora - his former teacher and mentor - to appreciate not only the effect of light on forms (Távora himself admitted to being an avid admirer of Le Corbusier), but also to stroll about the shadows in traditional habitats (Távora would gather important teachings from Japanese architecture during his grand tour in 1960 and filtering it through another great influence of his: Frank Lloyd Wright.

These different "phantom-characters" would come to also occupy the imagination of the young Siza, and to them he added references to Alvar Aalto, Bruno Taut or Adolf Loos, at the moment of considering the relationship between the individual and the collective space, between the domestic and the monumental scale, between the window and the city.

The photographic work of Mark Durden and João Leal focusing on Álvaro Siza's work in Porto - now published by Scopio Newspaper - goes in search of not only this same game of shadows upon the target surfaces of the façades and the interiors of the buildings but also the multiplicity of transparencies and penumbras that unfold through their ample glazed windows.

The photographs do not shun the presence of nature, of the inhabitant, or of the citizen; to the contrary, they seek out these precise moments of the day in which, at the same time, 
the trees are reflected or cast shadows on Siza's architecture and in which the human presence-absence is revealed in the objects or graffiti left on it. It is as if, for Mark Durden and João Leal, Siza's works were blank pages waiting for daily life to be written or printed upon them.

This perspective "upon" the walls or "through" the windows of the building takes on a near ghost-like character, something that is reinforced by its colourless tone, intentionally created by overexposure to the milky light at dawn or dusk. In these images, one feels the spectral presence of Le Corbusier or Adolf Loos - depicted in the fenêtre en longueur, or in the small "eyes" of the Faculty of Architecture building - or perhaps Alvar Aalto or Bruno Taut, in the rhythm alternating between the stairs, verandas and galleries of the Bairro da Bouça. These phantoms "live" there, reminding us that the best architecture is always the result of a revisit with and a crisscrossing of countless memories.

Álvaro Siza never constructed his architecture by opposing the transparency of modernity and the shadow of tradition, or by placing the purity of form in opposition with the indeterminateness of its content. In fact, he has always been adept at integrating these concepts in a sensory and spatial equilibrium, in an elegy of light and shadows, as complementary parts of the same "learned game" (to return to Le Corbusier). The photographs of Mark Durden and João Leal are the best proof of this equilibrium and this praise. 


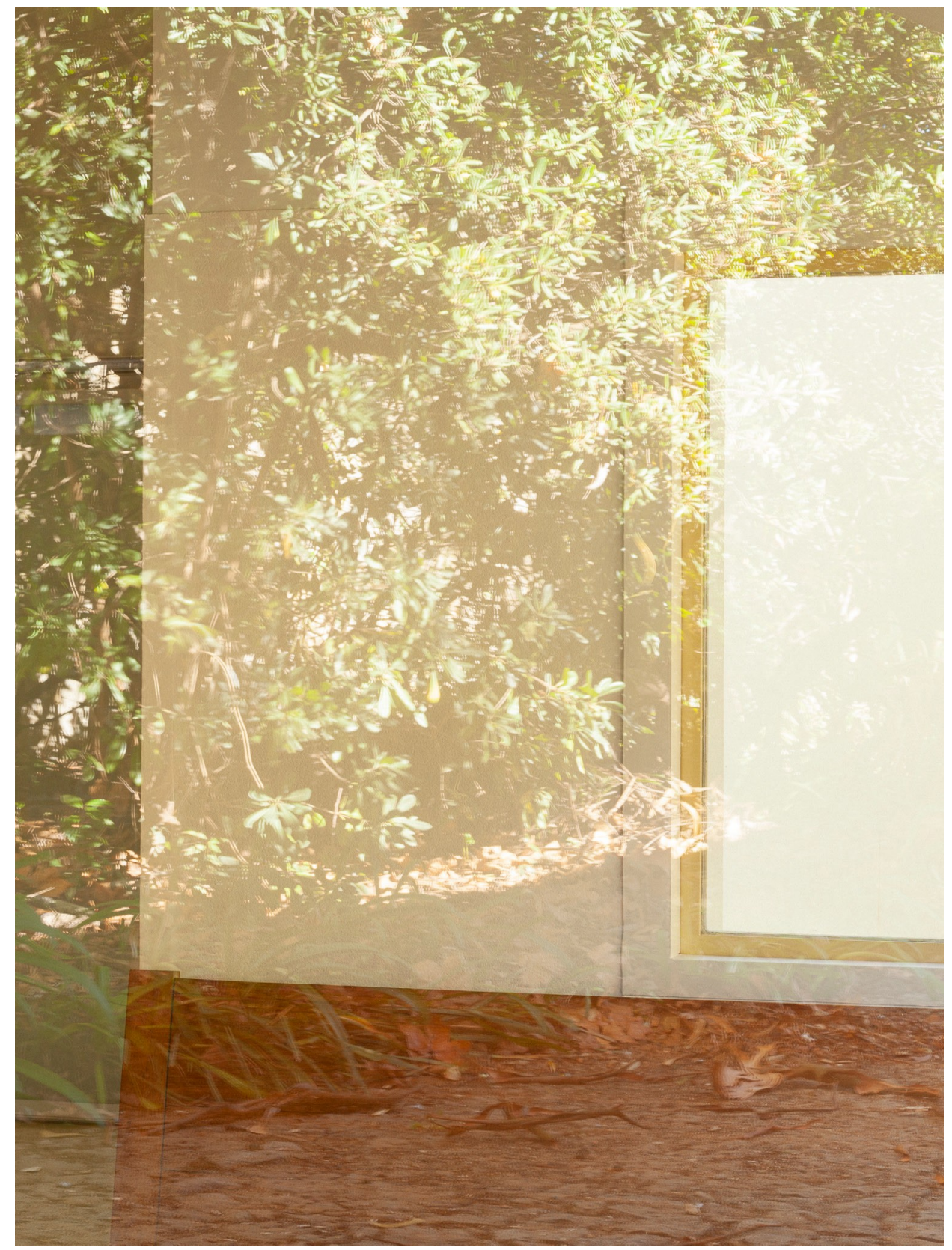




\section{Des yeux qui ne voient pas *}

\section{by António Choupina}

I must confess that - due to a broken foot - my enchantment with nature was somewhat faded. Staring at these photographs became an almost cathartic experience, serenity washing over in a dream, renewing a passion for the universe that created architecture and that, in turn, is recreated by it. If the Boa Nova Tea House were like Saramago's stone raft, adrift in a vast ocean, then the Serralves Museum would be like one of Cesário Verde's bucolic poems, bathed in idyllic foliage.

From the very first page, one discovers the building romantically dressed in seasonal vegetation, enveloped in a curtain of greenery, which drapes leaves as floating water lilies and droplets of rain. Distant windows seem to emerge beyond the sumptuous filter, manipulating a type of picturesque nostalgia: the primitive longing for a Garden of Eden or the simple magic of a child playing outside.

Having planted an oak tree in Serralves, this interpretation might be biased by my own boyish recollections or, perhaps, the landscape architect was just prone to episodes of refined apophenia. João Gomes da Silva was invited by Álvaro Siza to help mediate the relationship with Jacques Gréber's 1932 designs, supposedly inspired by the geometries of Versailles.

When Siza's Alhambra project was exhibited here, in 2017, I pointed out that Gréber's octagons and waterlines were connected to Granada - like those of Luis Barragán or Louis Kahn. In fact, all of Serralves can be viewed as a modern-day Alhambra and not because of its embellished gardens, protected by a stone wall, but because of its sequencing of spaces, of light and shade.

A luminous field is revealed upon arrival, framed by the mountainous profile of the auditorium, whose curvilinear elevation ambiguously approaches the gallery's obliquely cantilevered sunroof. A gravel courtyard follows suit, more intimately embracing a loquat tree and compressing half-light into vestibules. The limestone foyer might then be understood as a glass-covered cloister and, finally, its axis climaxes on the grassy southeast courtyard, between the two wings of the museum. 
A cubistic juxtaposing of volumes along these courtyards, overlaid longitudinally above the thalweg of the valley, manages to render this large container virtually imperceptible, cropped continuously by planes and treetops throughout a sixteen-meter geographic plunge. It's selfeffacing to an unheard of degree among 20th century institutions.

Only at the end does the museum fully take form, turning into a sort of white citadel that vanquishes its moat with a drawbridge, enacting all kinds of paradoxical mannerisms: contact through detachment, weightlessness through heaviness, asymmetry through axiality, et cetera. The bridge is a sculpture, especially now that one can no longer cross it - replaced by a crystal-shaped gift shop as gateway to the park.

Nature took charge, covering the ramp in a spontaneous pergola of branches, hiding the restaurant's once naked fenêtre en longueur. I remember it bareboned in 1999. It was my favorite moment and, for that reason, it's one of my favorite images by Mark Durden and João Leal. I could also mention a synaesthesia of silhouettes in shadow puppetry, while leaves rustled in melodic rhythm, or the emerald-green bushes, sucked inward in forced perspective and reflected back, as glassy palimpsests of themselves.

However, my most beloved photograph is the staff entrance. No, it's not the curved staircase of the $\mathbf{2 0 1 9}$ Cinema House, signaling the Art Deco tower of Marques da Silva's original villa. The future is the glade and a new museum wing, proposed by Álvaro Siza, which would bring deserved prominence to this unseen back wall, to its span, to its administrative courtyard, to its hierarchy of proportion and to its will vegetation - in the vein of Van Gogh's "Undergrowth with Two Figures".

The swirling tree bark of the Serralves Foundation is never-ending. Siza constantly awakens other sides of its reality, by skewing or deepening old and new viewpoints. "I'm sure that when Le Corbusier - himself a photographer, like Picasso, like Brancusi - said «des yeux qui ne voient pas», he thought, by opposition, in the multiplied capacity of seeing through a photographer's cultivated eye." **

\footnotetext{
* "Eyes that do not see" was published by Le Corbusier, in 1923, as part of "Vers une architecture".

** Álvaro Siza, in "L'Esperienza dei Luogui" exhibition catalogue. Edit.: Centro Cultural de Belém. 1997
} 